\title{
Efektivitas Model Pelatihan Keterampilan berbasis Usaha Pertanian-Peternakan Terpadu Pasca Bencana Erupsi Gunung Merapi di Kecamatan Selo, Kabupaten Boyolali
}

\author{
Shanti Emawati ${ }^{1}$, Lutojo $^{1}$, Heru Irianto ${ }^{2}$, Endang Tri Rahayu ${ }^{1}$ dan Ayu Intan Sari ${ }^{1}$ \\ ${ }^{1}$ Jurusan Peternakan, Fakultas Pertanian, Universitas Sebelas Maret \\ ${ }^{2} J u r u s a n$ Agribisnis, Fakultas Pertanian, Universitas Sebelas Maret \\ Jl. Ir. Sutami No.36A, Kentingan, Jebres, Surakarta 57126 \\ E-mail :shanti_uns@yahoo.co.id
}

\begin{abstract}
ABSTRAK
Tujuan dari penelitian ini adalah mengetahui keefektifan model pelatihan keterampilan berbasis usaha pertanian-peternakan terpadu di Kecamatan Selo, Kabupaten Boyolali. Metode penelitian ini menggunakan pendekatan Research and Development dengan teknik pengumpulan data secara observasi, dokumentasi dan wawancara. Uji coba model pelatihan menggunakan PreExperimental Design dengan One Group Pretest-Posttest Design. Data dianalisis dengan menggunakan analisis statistic non parametrik yaitu uji Wilcoxon Match Pairs Test. Hasil uji diperoleh peningkatan yang signifikan dari aspek kognitif, psikomotorik dan afektif. Hasil penelitian menunjukkan bahwa berdasarkan analisis menggunakan uji Wilcoxon dengan membandingkan antara hasil pretest dan posttest pada ketiga aspek yaitu aspek pengetahuan, ketrampilan dan sikap menunjukkan hasil yang signifikan, ini berarti terdapat perubahan atau peningkatan kemampuan peserta setelah diberikan pelatihan ketrampilan, sehingga dapat disimpulkan bahwa pelatihan ketrampilan usaha pertanian-peternakan terpadu di Kecamatan Selo, Kabupaten Boyolali efektif memberdayakan petani peternak.
\end{abstract}

Kata kunci : model pelatihan ketrampilan, usaha pertanian-peternakan terpadu, pasca erupsi Gunung Merapi, pemberdayaan, pemulihan kondisi sosial ekonomi

\section{Effectiveness of Skills Training Model Based on Integrated Crop-Livestock Post-Eruption of Mount Merapi in Selo, Boyolali}

\begin{abstract}
The purpose of this study was to determine the effectiveness of skills training model based integrated crop-livestock system in Selo, Boyolali. This research method using the approach of Research and Development with data collection techniques of observation, documentation and interviews. Test of training model using Pre-Experimental Design with One Group Pretest-Posttest Design. Data were analyzed using the nonparametric statistical analysis Wilcoxon Match Pairs Test. The test results obtained significant improvement of cognitive, psychomotor and affective. The results showed that based on analysis using Wilcoxon test by comparing the results of pretest and posttest on all three aspects: knowledge, skills and attitudes showed significant results, this means there is a change or an increase in the ability of the participants after being given skills training so that it can be concluded that the skills training of integrated crop-livestock system in Selo, Boyolali effectively empower farmers.
\end{abstract}

Keywords: model of skills training, integrated crop-livestock system, post-eruption of Mount Merapi, empowerment, socio-economic recovery 


\section{PENDAHULUAN}

Kabupaten Boyolali merupakan salah satu wilayah yang terkena dampak letusan Gunung Merapi. Erupsi Gunung Merapi tersebut menimbulkan kerugian besar dalam bidang pertanian hortikultura dengan kerusakan seluas lebih dari 1.100 hektar di Kecamatan Selo, Cepogo, dan Kemusuk. Kerusakan terparah dialami para petani yang berada di dalam kawasan rawan bencana tiga di Kecamatan Selo seperti Desa Lencoh, Desa Klakah, dan Desa Jrakah yang hanya berjarak kurang dari $7 \mathrm{~km}$ dari puncak Gunung Merapi. Selain itu disektor peternakan juga mengalami kerugian yaitu dari jumlah populasi sebesar 61 ribu ekor untuk sapi perah dan 81,5 ribu ekor sapi potong yang terkena dampak bencana erupsi Gunung Merapi sekitar 28,504 ribu ekor (Kompas, 2010).

Paradigma pendekatan penanggulangan bencana yang menilai bahwa korban bencana merupakan pihak yang tidak berdaya sudah saatnya dirubah menjadi penanggulangan bencana yang bersifat pemberdayaan. Penanggulangan bencana yang dilakukan harus memandang korban sebagai manusia yang aktif dengan kapasitas dan latar belakang serta motivasi dan sikapnya masing-masing. Dengan demikian, dalam implementasinya pemberian bantuan yang bersifat fisik dan temporer dengan tujuan pemulihan kondisi selayaknya dilengkapi dengan pemberian bantuan yang bersifat memberdayakan masyarakat di masa mendatang. Oleh karena itu berbagai upaya penanggulangan bencana hendaknya mempertimbangkan dampak jangka panjang serta menghormati gagasan dan kapasitas yang ada pada masyarakat dengan tujuan mengurangi kerentanan dalam jangka panjang dan meningkatkan kapasitas masyarakat.

Salah satu program pemberdayaan dengan menekankan peningkatan kapasitas masyarakat dapat dilakukan melalui skill empowerment, yaitu suatu program perumusan perumusan model pelatihan ketrampilan sebagai upaya pemberdayaan masyarakat. Melalui perumusan model pemberdayaan masyarakat ini akan diperoleh formula yang tepat untuk meningkatkan ketrampilan dan motivasi masyarakat untuk dapat merintis atau membangun kembali usaha sehingga dapat segera bangkit dari bencana (Royat, 2009). Usaha pertanian tanaman holtikultura dan peternakan sapi dijadikan tumpuan hidup bagi masyarakat lereng pegunungan Merapi. Masyarakat menjalankan usaha pertanian dan peternakan secara berdampingan yaitu sebagai mata pencaharian utama dan sampingan, namun sebagian besar masyarakat belum mampu mengintegrasikan keduanya sebagai suatu usaha yang saling terkait dan mendukung atau sering disebut dengan istilah pertanian-peternakan terpadu (integrated crop livestock system).

Keterampilan usaha terpadu merupakan perpaduan dari jenis keterampilan tertentu yang dijadikan sebagai sumber usaha dan keberadaannya memiliki hubungan yang saling mendukung antara satu jenis keterampilan dengan keterampilan lain. Kegiatan pelatihan keterampilan usaha terpadu disusun bersama antara warga belajar dengan tutor dan melibatkan berbagai sumberdaya yang tersedia dan dilaksanakan atas dasar kebutuhan. Pemilihan jenis keterampilan usaha yang diberikan ke masyarakat, dipilih dengan memperhatikan aspek-aspek seperti: (1) pelatihannya dirancang berdasarkan hasil identifikasi kebutuhan belajar masyarakat setempat; dan (2) memperhatikan kesesuaian antara kebutuhan atau jenis keterampilan dengan potensi sumberdaya yang ada (Sudirman, 2007). Berdasarkan latar belakang tersebut, maka perlu dilakukan penelitian yang bertujuan untuk mengetahui keefektifan model pelatihan keterampilan berbasis usaha pertanian-peternakan terpadu di Kecamatan Selo Boyolali.

\section{MATERI DAN METODE}

Penelitian ini dilaksanakan di Kecamatan Selo, Kabupaten Boyolali dari bulan April sampai dengan September 2011. 
Pemilihan lokasi penelitian menggunakan metode purposive sampling, yaitu suatu cara penentuan lokasi penelitian berdasarkan beberapa pertimbangan sesuai dengan tujuan penelitian Sugiyono (2006), yaitu : Kecamatan Selo, Kabupaten Boyolali merupakan wilayah berada paling dekat dengan puncak Gunung Merapi dan memiliki potensi pengembangan pertanian dan peternakan.

Penelitian ini merujuk pada penelitian yang dilakukan Sudirman (2007) cit Borg dan Gall (1989) dan Fraenkel dan Wallen (1993), yaitu menggunakan pendekatan Penelitian Pengembangan dengan tujuan untuk menghasilkan model pelatihan ketrampilan yang efektif sebagai upaya pemberdayaan, sehingga kemampuan masyarakat dapat berkembang. Teknik pengumpulan data dalam penelitian ini adalah observasi, dokumentasi serta wawancara.

Desain penelitian ini menggunakan Pre-Experimental Design dengan One Group Pretest dan Posttest Design. Penggunaan desain ini bertujuan untuk menguji keefektifan model pelatihan keterampilan usaha pertanian-peternakan terpadu. Pengujian keefektifan model dilakukan terhadap model konseptual yang dikembangkan sehingga dapat menghasilkan model empirik. Desain ini dilakukan dengan membandingkan hasil pretest dan posttest dari responden sebagai peserta pelatihan ketrampilan. Model eksperimen yang digunakan dalam penelitian ini dapat dilihat pada Gambar 1.

Data dianalisis menggunakan analisis statistik nonparametrik yaitu dengan uji Wilcoxon Match Pairs Test (Siegel, 1997 dan Sugiyono, 2001). Uji ini untuk mengetahui perbedaan antara sebelum dan sesudah diberikan pelatihan. Pengujian dilakukan dengan mentransformasi data kualitatif yang berbentuk skala likert ke dalam data kuantitatif. Hasil pengujian ini untuk membuktikan keefektifan dari model pelatihan ketrampilan usaha pertanian- peternakan terpadu yang telah disusun (Sudirman, 2007).

\section{HASIL DAN PEMBAHASAN}

\section{Keadaan Umum Lokasi Penelitian}

Secara topografi Kabupaten Boyolali terletak antara $110^{\circ} 22^{\prime} \mathrm{BT}-110^{\circ} 50^{\prime} \mathrm{BT}$ dan $7^{\circ} 36^{\prime}$ LS - $7^{\circ} 71^{\prime}$ LS dengan ketinggian antara 100 meter sampai dengan 1.500 meter dari permukaan laut. Kecamatan Selo yang berada di kaki Gunung Merapi dan Merbabu umumnya beriklim tropis dan mempunyai 2 musim, yaitu hujan dan kemarau yang silih berganti. Secara umum Kecamatan Selo merupakan perbukitan bergelombang dengan relief halus hingga sedang. Kemiringan lereng bervariasi dari $0 \%$ s/d lebih dari 70\%. Geomorfologi Kecamatan Selo merupakan perbukitan bergelombang berelief halus hingga kasar antara 400 hingga 1.400 meter diatas permukaan laut, yang terbagi menjadi 2 satuan geomorfologi, yaitu perbukitan berelief halus-datar (menempati wilayah bagian timur dan memanjang ke arah tenggara) dan perbukitan berelief sedang (bagian tengah hingga barat daya dan barat laut).

Secara administratif Kecamatan Selo terbagi menjadi 10 desa dan 53 dusun dengan luas daerah sebesar 5.697.724 ha. Kecamatan Selo berbatasan sebelah Utara dengan Kecamatan Ampel, sebelah Timur dengan Kecamatan Cepogo, sebelah Selatan dengan Kabupaten Klaten dan sebelah Barat berbatasan dengan Kabupaten Magelang. Jumlah penduduk di Kecamatan Selo adalah 28.594 jiwa dengan jumlah penduduk lakilaki adalah 14.092 jiwa, sedangkan jumlah penduduk perempuan sebesar 14.502 jiwa (BPS Kabupaten Boyolali, 2011).

Mata pencaharian penduduk sebagai besar pada sektor pertanian khususnya tanaman hortikultura (sayuran) dan tanaman perkebunan terutama tembakau. Gambaran potensi pertanian tanaman sayuran di Kecamatan Selo dapat dilihat pada Tabel 1. 


\begin{tabular}{|lcc|} 
Pengukuran & Perlakuan & Pengu \\
\hline 01 & $\mathrm{X}$ & $\mathrm{O} 2$ \\
\hline
\end{tabular}

Gambar 1. One Group Pretest-Posttest Design

Tabel 1. Luas lahan dan produksi tanaman sayuran di Kecamatan Selo

\begin{tabular}{lcc}
\hline \multicolumn{1}{c}{ Jenis sayuran } & Luas panen (ha) & Produksi (kw) \\
\hline Bawang merah & 152 & 19.450 \\
Daun bawang & 558 & 54.700 \\
Kentang & 18 & 3.120 \\
Wortel & 1.432 & 147.055 \\
Kobis & 1.073 & 115.840 \\
Sawi & 340 & 23.010 \\
Cabe & 84 & 7.674 \\
Tomat & 84 & 11.517 \\
Buncis & 134 & 7.894 \\
Mentimun & 49 & 5.823 \\
\hline
\end{tabular}

Sumber : Kabupaten Boyolali dalam Angka, 2010

Tabel 2. Potensi peternakan di Kecamatan Selo, Kabupaten Boyolali.

\begin{tabular}{lcc}
\hline \multicolumn{1}{c}{ Jenis ternak } & Jumlah pemilik (orang) & Jumlah ternak (ekor) \\
\hline Sapi potong & 1.463 & 2.295 \\
Sapi perah & 1.257 & 2.888 \\
Kambing & 194 & 641 \\
Domba & 115 & 368 \\
Kelinci & 4 & 172 \\
Ayam broiler & 3 & 16.000 \\
Ayam layer & 2 & 8.900 \\
Ayam buras & 5.965 & 32.810 \\
Itik & 45 & 363 \\
\hline
\end{tabular}

Sumber : Dinas Peternakan dan Perikanan Kabupaten Boyolali, 2010

Ditinjau dari kondisi geomorfologi, Kecamatan Selo memiliki potensi wilayah yang mendukung untuk perkembangan pariwisata, terutama berbasis peternakan. Gambaran mengenai potensi peternakan di Kecamatan Selo tersaji pada Tabel 2 sebagai berikut.

\section{Keefektifan Model Pelatihan Ketrampilan}

Hasil analisis deskritif diperkuat dengan analisis statistic nonparametrik.
Pertimbangan dipilihnya analisis tersebut adalah sampel penelitian diambil secara purposive (sengaja) dan jumlah sampel relative kecil yaitu hanya 10 orang, dimana dipilih petani peternak yang bisa mentranferkan ilmu yang diperoleh kepada petani peternak lainnya. Analisis statistic nonparametric yang digunakan dalam penelitian ini adalah analisis uji Wilcoxon Match Pairs Test. Analisis tersebut digunakan untuk melihat perkembangan pengetahuan, ketrampilan dan sikap petani peternak setelah mengikuti kegiatan 
pelatihan ketrampilan. Tingkat signifikansi dari aspek kognitif, afektif dan psikomorik dapat pula diuji menggunakan analisis statistik nonparametrik. Menurut Sugiyono (2001), dalam melakukan analisis statistik nonparametrik, data yang berbentuk ordinal ditranformasikan ke bentuk data nominal dan analisis yang digunakan menggunakan analisis uji Wilcoxon Match Pairs Test. Analisis data dilakukan dengan membandingkan nilai hasil pre-test dan postest untuk menguji signifikansi dua subyek penelitian berpasangan (Sudirman, 2007).

\section{Analisis uji Wilcoxon Match Pairs}

Test merupakan analisis pengujian efektivitas. Analisis tersebut dilakukan dengan memperhatikan sebagai berikut: 1) Hasil nilai skor aspek pengetahuan, sikap dan ketrampilan sebelum dan sesudah dilakukan kegiatan pelatihan ketrampilan, 2) Nilai total dan rata-rata dari ketiga aspek pengetahuan, sikap, ketrampilan. 3) Beda sebelum dan sesudah mengikuti pelatihan serta jenjang nilai dari masing-masing petani peternak yang mengikuti pelatihan (Sugiyono, 2001).

Berdasarkan hasil analisis data pretest dan posttest diperoleh hasil pada aspek kognitif, psikomotorik dan afektif.

\section{Aspek kognitif /pengetahuan}

Pada aspek kognitif tentang budidaya pertanian holtikultura, budidaya peternakan sapi, pengolahan pupuk organik dan biogas serta budidaya ikan lele, setelah dilakukan tes kepada petani peternak menunjukkan peningkatan yang signifikan. Hal ini terlihat pada nilai tes sebelum pelatihan sebesar 15,4 dan sesudah pelatihan 18,5 . Standar deviasi sebelum pelatihan 6,4 dan sesudah pelatihan 5,9. Nilai minimum sebelum pelatihan 8 , maksimum 24 dan nilai minimum sesudah pelatihan 10 dan maksimum sesudah pelatihan 25 .

Nilai hasil pretest dan posttest mengenai kemampuan kognitif yang dikuasai petani peternak sebagai peserta yang mengikuti pelatihan ketrampilan yang diuji dapat dilihat Tabel 3. Berdasarkan Tabel 3 hasil postest lebih besar dibandingkan dengan hasil pretest, hal ini berarti kegiatan pelatihan berpengaruh peningkatan kognitif petani peternak. Tabel 10 menunjukkan bahwa nilai jenjang terkecil adalah 0 (nol). Tabel kritis tes Wilcoxon untuk $\mathrm{n}=10$, taraf kesalahan 5\% (uji 2 pihak), maka $\mathrm{T}$ tabel $=8$. Disebabkan karena jumlah jenjang terkecil $=0$ dan lebih kecil dibandingkan 8, maka Ho ditolak. Hal ini berarti terdapat perbedaan kognitif sebelum dan sesudah mengikuti pelatihan.

Hasil uji Wilcoxon sebelum dan sesudah pelatihan secara deskriptif statistik tersaji pada Tabel 4. Hasil mean sesudah pelatihan $(18,5)$ lebih besar hasil mean sebelum pelatihan $(15,4)$. Hal ini berarti perbedaan pengetahuan yang dimaksud adalah adanya perubahan positif pengetahuan yang dimiliki petani peternak yang mengikuti pelatihan.

\section{Aspek psikomotor/ketrampilan}

Pada aspek ketrampilan berdasarkan observasi, petani peternak lebih trampil dalam melakukan budidaya pertanian holtikultura, budidaya peternakan sapi, pengolahan pupuk organik dan biogas serta budidaya ikan lele. Hal ini terlihat pada hasil observasi sebelum pelatihan sebesar 45,8 dan sesudah pelatihan 63. Standar deviasi sebelum pelatihan 26,1 dan sesudah pelatihan 28,8. Nilai minimum sebelum pelatihan 12, maksimum 84 dan nilai minimum sesudah pelatihan 24 dan maksimum sesudah pelatihan 96 .

Nilai hasil pretest dan posttest mengenai kemampuan psikomotor yang dikuasai petani peternak sebagai peserta yang mengikuti pelatihan ketrampilan yang diuji dapat dilihat Tabel 5. Hasil postest lebih besar dibandingkan dengan hasil pretest, berarti kegiatan pelatihan meningkatkan psikomotor petani peternak. Tabel 10 menunjukkan bahwa nilai jenjang terkecil adalah 0 (nol). Pada tabel kritis test Wilcoxon untuk $\mathrm{n}=10$, taraf kesalahan $5 \%$ (uji 2 pihak), maka $\mathrm{T}$ tabel $=8$ disebabkan karena jumlah jenjang terkecil $=0$ dan lebih kecil dibandingkan 8, maka Ho ditolak. Hal ini berarti terdapat perbedaan ketrampilan 
Tabel 3. Hasil pretest dan postest aspek kognitif

\begin{tabular}{ccccccc}
\hline \multirow{2}{*}{ Responden } & \multirow{2}{*}{ Pretest } & \multirow{2}{*}{ Posttest } & \multicolumn{3}{c}{ Beda } & \multicolumn{3}{c}{ Tanda jenjang } \\
\cline { 4 - 7 } & & & Pre \& post & Jenjang & + & - \\
\hline 1 & 21 & 24 & 3 & 4,5 & 4,5 & 0 \\
2 & 12 & 15 & 3 & 4,5 & 4,5 & 0 \\
3 & 20 & 23 & 3 & 6,5 & 6,5 & 0 \\
4 & 18 & 21 & 3 & 6,5 & 6,5 & 0 \\
5 & 8 & 11 & 3 & 8 & 8 & 0 \\
6 & 11 & 17 & 6 & 10 & 10 & 0 \\
7 & 9 & 14 & 5 & 9 & 9 & 0 \\
8 & 8 & 10 & 2 & 2,5 & 2,5 & 0 \\
9 & 23 & 25 & 2 & 2,5 & 2,5 & 0 \\
10 & 24 & 25 & 1 & 1 & 1 & 0 \\
\hline Jumlah & 154 & 185 & 31 & & 55 & \\
\hline Rata-rata & 15,4 & 18,5 & 3,1 & & T = 55 & 0 \\
\hline
\end{tabular}

Sumber : Data primer terolah, 2011

$\underline{\text { Tabel 4. Hasil uji Wilcoxon deskriptif statistik untuk aspek kognitif }}$

\begin{tabular}{llcccc}
\hline & N & Mean & Std deviasi & Min & Max \\
\hline Sebelum & 10 & 15,4 & 6,4 & 8 & 24 \\
Sesudah & 10 & 18,5 & 5,9 & 10 & 25 \\
\hline
\end{tabular}

Sumber : Data primer terolah, 2011

Tabel 5. Hasil pretest dan posttest aspek psikomotor

\begin{tabular}{ccccccc}
\hline \multirow{2}{*}{ Responden } & \multirow{2}{*}{ Pretest } & Posttest & \multicolumn{2}{c}{ Beda } & \multicolumn{3}{c}{ Tanda Jenjang } \\
\cline { 4 - 7 } & & & Pre \& post & Jenjang & + & - \\
\hline 1 & 78 & 92 & 14 & 6 & 6 & 0 \\
2 & 40 & 60 & 20 & 8 & 8 & 0 \\
3 & 52 & 62 & 10 & 1 & 1 & 0 \\
4 & 48 & 60 & 12 & 2,5 & 2,5 & 0 \\
5 & 12 & 24 & 12 & 2,5 & 2,5 & 0 \\
6 & 84 & 96 & 12 & 4,5 & 4,5 & 0 \\
7 & 16 & 32 & 16 & 7 & 7 & 0 \\
8 & 12 & 24 & 12 & 4,5 & 4,5 & 0 \\
9 & 52 & 84 & 32 & 9,5 & 9,5 & 0 \\
10 & 64 & 96 & 32 & 9,5 & 9,5 & 0 \\
\hline Jumlah & 458 & 630 & 172 & & 55 & 0 \\
\hline Rata-rata & 45,8 & 63 & 17,2 & & T =55 & 0 \\
\hline Surnyyyyy
\end{tabular}

Sumber : Data primer terolah, 2011 
Tabel 6. Hasil uji Wilcoxon deskriptif statistik untuk aspek psikomotor

\begin{tabular}{llcccc}
\hline & N & Mean & Std deviasi & Min & Max \\
\hline Sebelum & 10 & 45,8 & 26,1 & 12 & 84 \\
Sesudah & 10 & 63 & 28,8 & 24 & 96 \\
\hline
\end{tabular}

Sumber : Data primer terolah, 2011

Tabel 7. Hasil pretest dan posttest aspek sikap

\begin{tabular}{|c|c|c|c|c|c|c|}
\hline \multirow{2}{*}{ Responden } & \multirow{2}{*}{ Pretest } & \multirow{2}{*}{ Posttest } & Beda & \multicolumn{3}{|c|}{ Tanda Jenjang } \\
\hline & & & Pre \& post & Jenjang & + & - \\
\hline 1 & 23 & 30 & 7 & 4,5 & 6 & 0 \\
\hline 2 & 13 & 20 & 7 & 4,5 & 8 & 0 \\
\hline 3 & 33 & 40 & 7 & 6,5 & 1 & 0 \\
\hline 4 & 20 & 23 & 3 & 1 & 2,5 & 0 \\
\hline 5 & 13 & 20 & 7 & 6,5 & 2,5 & 0 \\
\hline 6 & 13 & 27 & 13 & 8,5 & 4,5 & 0 \\
\hline 7 & 20 & 27 & 7 & 2,5 & 7 & 0 \\
\hline 8 & 13 & 20 & 7 & 2,5 & 4,5 & 0 \\
\hline 9 & 20 & 33 & 13 & 8,5 & 9,5 & 0 \\
\hline 10 & 27 & 40 & 13 & 10 & 10 & 0 \\
\hline Jumlah & 196 & 280 & 83 & & 55 & 0 \\
\hline Rata-rata & 19,6 & 28 & 8,3 & & $\mathrm{~T}=55$ & 0 \\
\hline
\end{tabular}

Sumber : Data primer terolah, 2011

Tabel 8. Hasil uji Wilcoxon deskriptif statistik untuk aspek sikap

\begin{tabular}{lccccc}
\hline & N & Mean & Std deviasi & Min & Max \\
\hline Sebelum & 10 & 19,6 & 6,7 & 13 & 33 \\
Sesudah & 10 & 28 & 7,7 & 20 & 40 \\
\hline
\end{tabular}

Sumber : Data primer terolah, 2011

sebelum dan sesudah mengikuti pelatihan. Hasil uji Wilcoxon sebelum dan sesudah pelatihan secara deskriptif statistik tersaji pada Tabel 6. Berdasarkan Tabel 6, hasil mean sesudah pelatihan (63) lebih besar hasil mean sebelum pelatihan $(45,8)$. Hal ini berarti perbedaan ketrampilan yang dimaksud adalah adanya perubahan positif ketrampilan yang dimiliki petani peternak yang mengikuti pelatihan.

\section{Aspek Afektif/sikap}

Pada aspek sikap hasil nilai sebelum pelatihan sebesar 19,6 dan sesudah pelatihan 28. Standar deviasi sebelum pelatihan 6,7 dan sesudah pelatihan 7,7. Nilai minimum sebelum pelatihan 13, maksimum 33 dan nilai minimum sesudah pelatihan 20 dan maksimum 40 .

Nilai hasil pretest dan posttest kemampuan sikap yang dikuasai petani peternak sebagai peserta yang mengikuti pelatihan ketrampilan yang diuji dapat dilihat Tabel 7. Hasil posttest lebih besar dibandingkan dengan hasil pretest, berarti kegiatan pelatihan meningkatkan sikap petani peternak. Tabel 7 menunjukkan bahwa nilai jenjang terkecil adalah 0 (nol). 
Tabel kritis test Wilcoxon untuk $\mathrm{n}=10$, taraf kesalahan 5\% (uji 2 pihak), maka T tabel $=8$ disebabkan jumlah jenjang terkecil $=0$ dan lebih kecil dibandingkan 8 , maka Ho ditolak, menunjukkan perbedaan sikap sebelum dan sesudah mengikuti pelatihan. Hasil uji Wilcoxon sebelum dan sesudah pelatihan tersaji pada Tabel 8. Hasil mean sesudah pelatihan $(19,6)$ lebih besar hasil mean sebelum pelatihan (28). Hal ini berarti perbedaan sikap yang dimaksud adalah adanya perubahan positif ketrampilan peternak yang mengikuti pelatihan.

Berdasarkan uji Wilcoxon, hasil pretest dan posttest dari yaitu aspek pengetahuan, ketrampilan dan sikap sesudah pelatihan lebih besar dibandingkan dengan hasil sebelum pelatihan. Hal ini sesuai dengan yang dikemukakan Sudirman (2007), bahwa pemberian pelatihan ketrampilan usaha pertanian-peternakan terpadu mampu memberikan perubahan positif kepada masyarakat petani peternak, yang berarti model pelatihan ketrampilan usaha pertanian-peternakan terpadu di Kecamatan Selo, Kabupaten Boyolali dalam memberdayakan masyarakat dengan mengembangkan kemampuan berusaha terbukti efektif.

\begin{tabular}{ccc}
\multicolumn{3}{c}{ KESIMPULAN } \\
Berdasarkan & hasil & analisis \\
menggunakan uji & Wilcoxon & dengan
\end{tabular}

membandingkan antara hasil pretest dan posttest pada ketiga aspek yaitu aspek pengetahuan, ketrampilan dan sikap menunjukkan hasil yang signifikan. Hal ini berarti terdapat perubahan atau peningkatan kemampuan peserta setelah diberikan pelatihan ketrampilan, sehingga dapat disimpulkan bahwa pelatihan ketrampilan usaha pertanian-peternakan terpadu di Kecamatan Selo, Kabupaten Boyolali efektif memberdayakan masyarakat.

\section{DAFTAR PUSTAKA}

Borg, W.R dan M.D.Gall. 1989. Educational Research. Pinancing. New York.

Fraenkel, J.R.1993. How To Design and Evaluate Research in Education. McGrawHill. Singapura

Siegel, S. 1997. Statistik Nonparametrik untuk Ilmu-ilmu Sosial. Gramedia Pustaka Utama. Jakarta.

Sudirman. 2007. Model Pelatihan Keterampilan Usaha Terpadu bagi Petani sebagai Upaya Alih Komoditas Studi pada Petani Penggarap Lahan Perhutani di Desa Suntenjaya Kabupaten Bandung. Desertasi. UPI. Bandung.

Sugiyono. 2001. Statistik Nonparametrik untuk Penelitian. Alfabeta. Bandung

Sugiyono. 2006. Metode Penelitian Bisnis. Cetakan 9. CV Alfabeta. Bandung. Susieni, A. 2003. Studi Kelayakan Bisnis. Cetakan 2. Penerbit Andi. Yogyakarta. 